\title{
Manuel Martín Riego, Colegio de la Sagrada Familia de Sevilla (1895- 2020). 125 años de presencia Vedruna, Sevilla, Colegio de la Sagrada Familia de Sevilla. Carmelitas de la Caridad, 2020, 317 pp.
}

No es la primera vez que el autor de la obra, reconocido especialista en Historia de la Iglesia Moderna y Contemporánea, con numerosos trabajos publicados a lo largo de su dilatada trayectoria profesional como docente e investigador, se ha sumergido para desentrañar la historia de la presencia de las Carmelitas de la Caridad en la ciudad de Sevilla. En esta ocasión lo hace con motivo del 125 aniversario de la instalación del colegio en el popular barrio de la Macarena; una apertura que se hacía entonces, cuando ya existía desde hacía varios años en la ciudad el Colegio San Joaquín (luego Santa Joaquina) de la misma congregación, pero el que ahora iniciaba su andadura lo hacía allí donde abundaba la pobreza, con un alto nivel de analfabetismo en el barrio, en particular en las mujeres que eran las más perjudicadas en todo lo relativo a la educación. Por la estrecha vinculación que tiene el autor con el colegio desde 1976, cuando inició aquí su oficio como profesor y continúa relacionado a pesar del tiempo transcurrido, se nota que la obra esta hecha con mucho cariño habiendo considerado una distinción y un deber acometer la empresa que es referenciada. Las letras de agradecimiento del autor por todo lo que ha recibido del colegio y de la Congregación que figuran al final de la introducción son suficientemente ilustrativas al respecto.

El soporte archivístico y documental que fundamenta la obra no es desdeñable. Ha contado para realizarla la abundante documentación existente en el Fondo Arzobispal del Archivo General del Arzobispado de Sevilla, tanto en la antigua sección de Órdenes y Congregaciones Religiosas como en la sección de Asuntos Despachados, sumando el medio centenar de legajos los consultados. La documentación propia de la congregación también es abundante, en el del Colegio de Santa Joaquina Vedruna como en el Colegio de la Sagrada Familia, ambos bastante completos, lo que permiten trazar -sin más dificultad que el poner empeño en hacerlo- toda la historia del instituto en Sevilla. No menor es también el aporte bibliográfico y el de las fuentes editadas (éste, básicamente la información que facilita el boletín eclesiástico y los distintos estadillos sobre el estado general del instituto religioso 
en las últimas décadas); conviene referir sobre lo primero que el autor fue pionero en esta archidiócesis en los estudios sobre la formación del clero, pero también -junto a otros- a la hora de estudiar el marco general de los estudios de las órdenes y congregaciones religiosas establecidas en Sevilla durante la Edad Moderna y Contemporánea de las que, ahora, efectúa un análisis sobre una realidad concreta. Ambas circunstancias, disponibilidad de fuentes y conocimiento sobre la temática del autor, constituyen sin duda elementos que nos ponen en situación de lo que cabe esperar de la obra.

El libro se articula en dos partes claramente diferenciadas y de desigual extensión. En la primera, que ocupa casi un tercio del total, el autor nos sitúa ante la realidad preexistente cuando Vedruna asume el Colegio de la Sagrada Familia en 1895. Articulada esta parte en dos capítulos comienza por mostrarnos primeramente las congregaciones religiosas existentes en la archidiócesis de Sevilla a lo largo de los siglos XVIII y XIX distinguiendo con precisión de relojero suizo: lo que eran las escuelas dominicales y nocturnas de obreros, los distintos patronatos, las fundaciones de congregaciones religiosas que llevaban el carisma de la educación, tanto las creadas en España como las que fueron surgiendo en Sevilla, concluyendo con el estado de la educación femenina en Sevilla a comienzos del novecientos. En el segundo capítulo de esta primera parte, nos sitúa ahora en la Congregación de las Carmelitas de la Caridad: la figura de la fundadora, la fundación de la congregación, la expansión del instituto desde 1826 y las distintas vicisitudes vividas desde entonces hasta la actualidad. De la realidad Vedruna en el marco andaluz hace un apartado expreso, bastante exhaustivo, en el que se nos traza cómo la congregación se comenzó su instalación en Cádiz (en la capital y ciudades de San Fernando, Jerez de la Frontera, Puerto Real, El Puerto de Santa María y Cantarranas, ya más recientemente, de inserción), Sevilla (Écija, los ya citados colegios de San Joaquín instalado inicialmente en el centro -más tarde trasladado al barrio de Nervión- y de la Sagrada Familia en Sevilla y, en la misma ciudad, una comunidad de inserción), Córdoba (Lucena), Jaén (Jaén y Úbeda) y Huelva (La Palma del Condado). Podía el autor haberse centrado exclusivamente en el Colegio de la Sagrada Familia, pero queda claro que, con esta adecuada introducción sobre la educación religiosa femenina y las congregaciones religiosas dedicadas a ello, se 
contextualiza convenientemente esta realidad permitiendo tener una aproximación más exacta del suceso.

La segunda parte, la más extensa que dobla a esta otra ciertamente introductoria, está dedicada por completo a la historia del colegio; mejor deberíamos decir como más arriba se ha adelantado a la presencia desde 1895 de las Carmelitas de la Caridad en el Colegio de la Sagrada Familia existente en la calle Pozo de Sevilla, institución educativa que había sido puesta en marcha en 1869 para la educación de niñas pobres por el P. Esclapés, SJ, que quiso así contrarrestar los proyectos educativos que los protestantes tenían establecidos en la misma collación. Cinco hermanas de las que estaban en el entonces Colegio de San Joaquín se hicieron cargo del colegio, aceptaron todo lo existente incluido el oratorio y las testamentarias que podían sostenerlo. El éxito estuvo asegurado desde el primer momento cuando el número de alumnas ascendía a los tres centenares.

En tres grandes apartados se vertebra esta segunda parte. En el primero de ellos se aborda la historia del colegio hasta 1975. Aparte de la presencia de la congregación, las dos figuras más sobresalientes del mismo son el P. Esclapés, fundador del mismo y quien pidió años más tarde que se hicieran estas religiosas cargo del mismo, y también doña Gertrudis Zuazo Zuazo, benefactora del centro y creadora de la Fundación para el mantenimiento del establecimiento escolar; la dotación del mismo estuvo asegurado en las testamentarias, bienes y valores de la familia (algunos de ellos de origen indiano) y otras rentas. También los informes enviados a la Junta Provincial de Beneficencia sobre el edificio, el objeto de la Fundación, el número de alumnas y religiosas. Y, por último, relativo a todos estos años el fin fundamental del colegio que no era sino lo estudios y alimentación de las seis niñas internas naturales de Sevilla y huérfanas de padre y madre.

En los otros dos grandes apartados de esta segunda parte se abordan los últimos cuarenta años. Se hace de una manera ciertamente original como es, por un lado, el historiar el colegio a partir de las instituciones educativas internas, lo que nos lleva a conocerlo a través de los estatutos e ideario del mismo y, de otro, a través del carisma educativo Vedruna desde la impronta que la fundadora procuró para su instituto en lo referido a la formación de los alumnos. El análisis del Consejo de Centro, del Consejo de Educación Cristiana, del Consejo Escolar permiten conocer la representatividad, 
la corresponsabilidad y la globalidad de la institución; también la convivencia, la organización escolar y las actividades que se celebran, entre las que no podían faltar las religiosas. En la investigación se ha utilizado, entre otra documentación, los libros de actas de los claustros de profesores como medio para conocer la historia del centro. No solo se ha analizado los organismos propiamente internos sino también aquellos otros como la Asociación de Padres, de la que se tiene documentación desde 1980, en la que puede cotejarse que la colaboración con el colegio no sólo es en lo material sino en todo cuanto se relaciona con la educación de los estudiantes.

Importante es sin duda el tercer gran apartado de la segunda parte. Bajo el título ciertamente solemne de Carisma Educativo Vedruna el autor pone en relación el proyecto y propuestas educativas del colegio con el común para todos los colegios Vedruna en el mundo, siempre adaptadas a las particularidades de cada país; y todo esto, como no podía ser de otra manera, con la misión evangelizadora de la Iglesia que debe impregnar todo el programa escolar y a los distintos miembros de la comunidad (alumnos, profesorado y padres) como bien sintetiza el autor de la obra. Es por eso que el proyecto pastoral y evangelizador de la escuela Vedruna se analiza a partir del Magisterio de la Iglesia en estos aspectos. Las actividades pastorales del centro (retiros, ejercicios espirituales, primeras comuniones, confirmaciones, eucaristías, convivencia y otras) no son por ello algo secundario, sino que constituyen parte fundamental en la formación que reciben los alumnos de este centro (e igual en los otros de Vedruna) que requieren de una imprescindible coordinación pastoral.

No está de más añadir que la obra está muy bien escrita, lo que permite una lectura ágil facilitada con el tipo empleado y el formato elegido; está además ampliamente ilustrada. Pero eso no es lo más importante: frente a obras que nos trasladan infinidad de datos (a lo que somos muy proclives algunos) se nota en la que referenciamos que se ha hecho"desde dentro", con un conocimiento profundo de la institución, pero también de lo que debe ser un colegio católico, vinculado por tanto a la Iglesia a través del espíritu propio Vedruna. Eso es lo verdaderamente importante además de original, porque podrá servir de ejemplo a otras obras de la misma naturaleza. Por ello y por muchas cosas más, mi más sincera felicitación al autor y a la institución que lo ha patrocinado.

José-Leonardo Ruiz Sánchez 